\title{
Article \\ Corrosion Behavior and Mechanical Properties of a Nanocomposite Superhydrophobic Coating
}

\author{
Divine Sebastian $^{1}\left(\right.$, , Chun-Wei Yao ${ }^{1, * \mathbb{D}}$, Lutfun Nipa ${ }^{1}$, Ian Lian ${ }^{2}$ and Gary Twu ${ }^{3}$ \\ 1 Department of Mechanical Engineering, Lamar University, Beaumont, TX 77710, USA; \\ dsebastian1@lamar.edu (D.S.); Inipa@lamar.edu (L.N.) \\ 2 Department of Biology, Lamar University, Beaumont, TX 77710, USA; ilian@lamar.edu \\ 3 Department of Biology, Washington University in St. Louis, St. Louis, MO 63130, USA; garytwu@wustl.edu \\ * Correspondence: cyao@lamar.edu; Tel.: +1-409-880-7008
}

Citation: Sebastian, D.; Yao, C.-W.; Nipa, L.; Lian, I.; Twu, G. Corrosion Behavior and Mechanical Properties of a Nanocomposite Superhydrophobic Coating. Coatings 2021, 11, 652. https://doi.org/10.3390/ coatings 11060652

Academic Editor:

Ioannis Karapanagiotis

Received: 11 May 2021

Accepted: 28 May 2021

Published: 29 May 2021

Publisher's Note: MDPI stays neutral with regard to jurisdictional claims in published maps and institutional affiliations.

Copyright: (c) 2021 by the authors. Licensee MDPI, Basel, Switzerland. This article is an open access article distributed under the terms and conditions of the Creative Commons Attribution (CC BY) license (https:/ / creativecommons.org/licenses/by/ $4.0 /)$.

\begin{abstract}
In this work, a mechanically durable anticorrosion superhydrophobic coating is developed using a nanocomposite coating solution composed of silica nanoparticles and epoxy resin. The nanocomposite coating developed was tested for its superhydrophobic behavior using goniometry; surface morphology using scanning electron microscopy and atomic force microscopy; elemental composition using energy dispersive $\mathrm{X}$-ray spectroscopy; corrosion resistance using atomic force microscopy; and potentiodynamic polarization measurements. The nanocomposite coating possesses hierarchical micro/nanostructures, according to the scanning electron microscopy images, and the presence of such structures was further confirmed by the atomic force microscopy images. The developed nanocomposite coating was found to be highly superhydrophobic as well as corrosion resistant, according to the results from static contact angle measurement and potentiodynamic polarization measurement, respectively. The abrasion resistance and mechanical durability of the nanocomposite coating were studied by abrasion tests, and the mechanical properties such as reduced modulus and Berkovich hardness were evaluated with the aid of nanoindentation tests.
\end{abstract}

Keywords: multiscale corrosion analysis; superhydrophobic coating; nanocomposite; AFM

\section{Introduction}

Corrosion as an engineering problem is of great significance, owing to the fact that corrosion alone is responsible for a huge portion of material loss and economic loss in the industrial world globally [1]. A material is susceptible to undergoing corrosion in its service life, and thus it is very essential to develop preventive methods to control the occurrence of corrosion and strategies to eliminate the corrosion process on engineering materials. Out of all the engineering materials in use today, aluminum can be considered as one of the most widely used materials, especially because of its outstanding material properties, such as good electrical conductivity, thermal conductivity, ductility, low density, and high strength to weight ratio. Aluminum is used in diverse applications, such as aircraft, automobiles, heat exchangers, and food containers. In all these applications, corrosion is a serious problem, and hence it is essential to address the same.

There are various ways by which corrosion can be controlled. These include electroplating [2], corrosion inhibitors [3], cathodic protection [4], and protective coating [5]. Protective coatings can be of various types, depending on the functionality that is responsible for effectively controlling corrosion. One of the advanced protective anticorrosion coatings is the superhydrophobic coating [6-8]. Superhydrophobic coatings are very efficient anticorrosion coatings because of their innate water repelling behavior and the effective barrier created between the corrosive environment and the metal to be protected. In addition to corrosion protection, superhydrophobic coatings have the capability to introduce other significant properties, such as anti-biofouling [9], self-cleaning [10], and anti-icing [11]. The major requirements for developing a superhydrophobic coating are 
high surface roughness, which can be achieved by alteration in the surface topography at micro/nanoscale [12], and low surface free energy, which can be achieved by alteration in surface chemistry [13]. Keeping these two requirements in mind, superhydrophobic coatings can be fabricated using different methods, such as nanocomposite coatings [14-17], chemical vapor deposition [18], self-assembled monolayers [19], and template method [20]. Nanocomposite coatings are receiving a great deal of attention, especially due to the good tunability of the coating by varying the constituents within the nanocomposite coating solution [21]. Regarding the fabrication process, nanocomposite coatings facilitate the fulfillment of the two requirements for superhydrophobic coatings-surface roughness and low surface free energy in a single step.

The main goal of this work was to develop a novel superhydrophobic nanocomposite coating, offering good corrosion resistance and durability. The nanocomposite coating solution for developing such coating was composed of functionalized silica nanoparticles, epoxy resin, and toluene. The degree of superhydrophobicity of the developed nanocomposite coating was evaluated by the measurement of static contact angle. To confirm the abrasion resistance of the developed nanocomposite coating, the same was tested using two different abrasion tests, where the abrading action was simulated by linear motion against 240 grit sandpaper and a standard abrader under specific applied pressures, and the results were compared against previously reported superhydrophobic coatings [22]. In addition to the abrasion tests, nanomechanical properties such as Berkovich hardness and reduced modulus for the developed superhydrophobic coating were measured to quantify the mechanical properties of the same. Another goal of this work was to confirm the corrosion resistance of the fabricated nanocomposite coating at higher resolution as well as using standard corrosion measurement technique such as potentiodynamic polarization test. The corrosion resistance of the fabricated coating was confirmed by the topography measurements performed on a selected area of the coating. This was done successively by atomic force microscopy after simulating accelerated corrosion using a potentiostat [23]. The same test was performed on bare aluminum alloy substrates for comparison. The corrosion parameters for both the nanocomposite coating and bare aluminum alloy substrate were measured by a potentiodynamic polarization test.

\section{Materials and Methods}

The substrates used for depositing the coating were 2024-T3 aluminum alloy plates of $2.5 \mathrm{~cm} \times 2.5 \mathrm{~cm} \times 0.5 \mathrm{~mm}$. Chemicals used were acetone (Sigma Aldrich, St. Louis, MO, USA), anhydrous ethanol (Sigma Aldrich, St. Louis, MO, USA), isopropyl alcohol (Sigma Aldrich, St. Louis, MO, USA), epoxy resin (105 Epoxy Resin, West Systems, Bay City, MI, USA), epoxy hardener (206 Slow Hardener, West Systems, Bay City, MI, USA). Silane-modified hydrophobic $\mathrm{SiO} 2$ nanoparticles (RX-50) with an average diameter of $55 \mathrm{~nm}( \pm 15 \mathrm{~nm})$ were obtained from Evonik, USA. All experiments were conducted at ambient temperature of $25^{\circ} \mathrm{C}$.

All the substrates were cleaned in a sequential manner prior to use as follows: ultrasonication was performed in acetone for a duration of $15 \mathrm{~min}$ followed by rinsing with isopropyl alcohol, ethanol, and deionized water sequentially to remove any surface contaminants or grease. The substrates were dried in air at ambient temperature. The nanocomposite coating solution was prepared according to the following procedure. $1.0 \mathrm{~g}$ of silica nanoparticle was mixed in $5 \mathrm{~g}$ of toluene, and then the suspension of nanoparticles in toluene was dispersed by using a planetary centrifugal mixer. The dispersion was mixed for $2 \mathrm{~min}$ at $1000 \mathrm{rpm}$ followed by defoaming for $1 \mathrm{~min}$ at $2200 \mathrm{rpm}$. $1 \mathrm{~g}$ of epoxy resin was added to the dispersion thus obtained and was further mixed for 2 min at $1000 \mathrm{rpm}$ followed by defoaming for $1 \mathrm{~min}$ at $2200 \mathrm{rpm}$ using the planetary centrifugal mixer. After this, $0.18 \mathrm{~g}$ of hardener was added to the dispersion obtained in the previous step and was again mixed for $2 \mathrm{~min}$ at $1000 \mathrm{rpm}$ followed by defoaming for $1 \mathrm{~min}$ at $2200 \mathrm{rpm}$ using the planetary centrifugal mixer. 
The substrates were then dip-coated in the prepared nanocomposite solution at $200 \mathrm{~mm} / \mathrm{min}$ speed using an automated dip coater. The substrate was immersed completely in the solution for $10 \mathrm{~s}$, and 3 cycles of this process were used for the dip-coating. The substrates coated with the nanocomposite coating solution was the cured in an oven at $45^{\circ} \mathrm{C}$ for $2 \mathrm{~h}$ and then cooled at room temperature under the fume hood.

The surface morphologies and elemental compositions of the nanocomposite superhydrophobic coating were assessed using a scanning electron microscope (SEM, JSM-7500F, JEOL, Peabody, MA, USA) equipped with energy-dispersive X-ray spectroscope, and the surface topography was analyzed using an atomic force microscope (AFM, Park NX10, Park System Co., Santa Clara, CA, USA). A computer software XEI was used for the extraction of the AFM scan images. The static water contact angles were measured using a drop shape analyzer (DSA25E, Krüss, Matthews, NC, USA). Water droplets of $10 \mu$ l volume were dropped onto the surfaces to be tested under ambient temperature and atmosphere. A manual linear abrasion test was carried out with the aid of 240-grit sandpaper with applied normal pressure of $7.75 \mathrm{kPa}$. An automated linear mechanical abrasion was performed with a linear abrader (Taber Industries, North Tonawanda, NY, USA) along with CS-10F Calibrase abradant under an applied normal pressure of $29.9 \mathrm{kPa}$. Nanomechanical measurements were performed using a nanoindenter (Hysitron TI 980, Bruker) with a diamond Berkovich tip as the indenter.

A potentiostat system (Autolab PGSTAT204, Metrohm, Riverview, FL, USA) was used to perform the potentiodynamic polarization measurement in a $3.5 \mathrm{wt} \%$ aqueous solution of $\mathrm{NaCl}$ at ambient temperature. A silver/silver chloride $(\mathrm{Ag} / \mathrm{AgCl})$ reference electrode, a platinum wire mesh electrode, and the test specimens were used as the reference electrode, counter electrode, and working electrode, respectively. The current density was measured by using the geometrical area of the working electrode exposed to the electrochemical cell during the polarization measurement, which was $0.79 \mathrm{~cm}^{2}$. The potentiodynamic polarization curve was recorded from -250 to $250 \mathrm{mV}$ versus the open circuit potential at a sweep rate of $1 \mathrm{mV} / \mathrm{s}$.

The nanoscale topography measurements were performed using AFM, with a scan rate of $0.30 \mathrm{~Hz}$. The cantilever probe used for the AFM measurements has an overall metallic coating (PtIr5) on both sides. The nominal resonance frequency of the cantilever probe used was $75 \mathrm{kHz}$, and the spring constant was $2.8 \mathrm{~N} / \mathrm{m}$. The accelerated corrosion between the successive AFM scans was carried out using a potentiostat system at $90 \mathrm{mV}$ versus open circuit potential for specific durations of accelerated corrosion with a $3.5 \mathrm{wt} \%$ aqueous solution of $\mathrm{NaCl}$ as the electrolyte.

\section{Results and Discussions}

\subsection{Effect of Nanoparticle/Epoxy Proportion}

Figure 1 shows the static contact angles obtained for various proportions of silica nanoparticles, with respect to the amount of epoxy resin. The use of $0.25 \mathrm{~g}$ of silica nanoparticles in $1 \mathrm{~g}$ of epoxy resin resulted in a contact angle of $118^{\circ}$, and a continuous increase in the static contact angle was observed upon increasing the amount of silica nanoparticles up to $1.0 \mathrm{~g}$ of silica nanoparticles. The use of $0.5 \mathrm{~g}$ of silica nanoparticles yielded a static contact angle of $139^{\circ} ; 0.75 \mathrm{~g}$ nanoparticles yielded a static contact angle of $145^{\circ}$; and $1.0 \mathrm{~g}$ of silica nanoparticles yielded a very high angle of $162^{\circ}$. A further increase in the amount of silica nanoparticles to $1.25 \mathrm{~g}$ of silica nanoparticles showed a decrease in the static contact angle. Hence, $1.0 \mathrm{~g}$ of silica nanoparticles was selected to use within the nanocomposite coating solution, along with $1 \mathrm{~g}$ of epoxy resin and $5 \mathrm{~g}$ of toluene. The static contact angle measurements were repeated over four arbitrarily selected locations, and by doing so, the superhydrophobic coating's uniformity was confirmed as the static contact angles measured were close to each other. The observations about the variation in contact angle with respect to the amount of nanoparticles within the nanocomposite coating solution were compared against similar observations made in previous studies, where 
the effect of silica nanoparticles in a nanocomposite coating solution was studied, and the results in Figure 1 were found to agree very well with previously reported results [24-26].

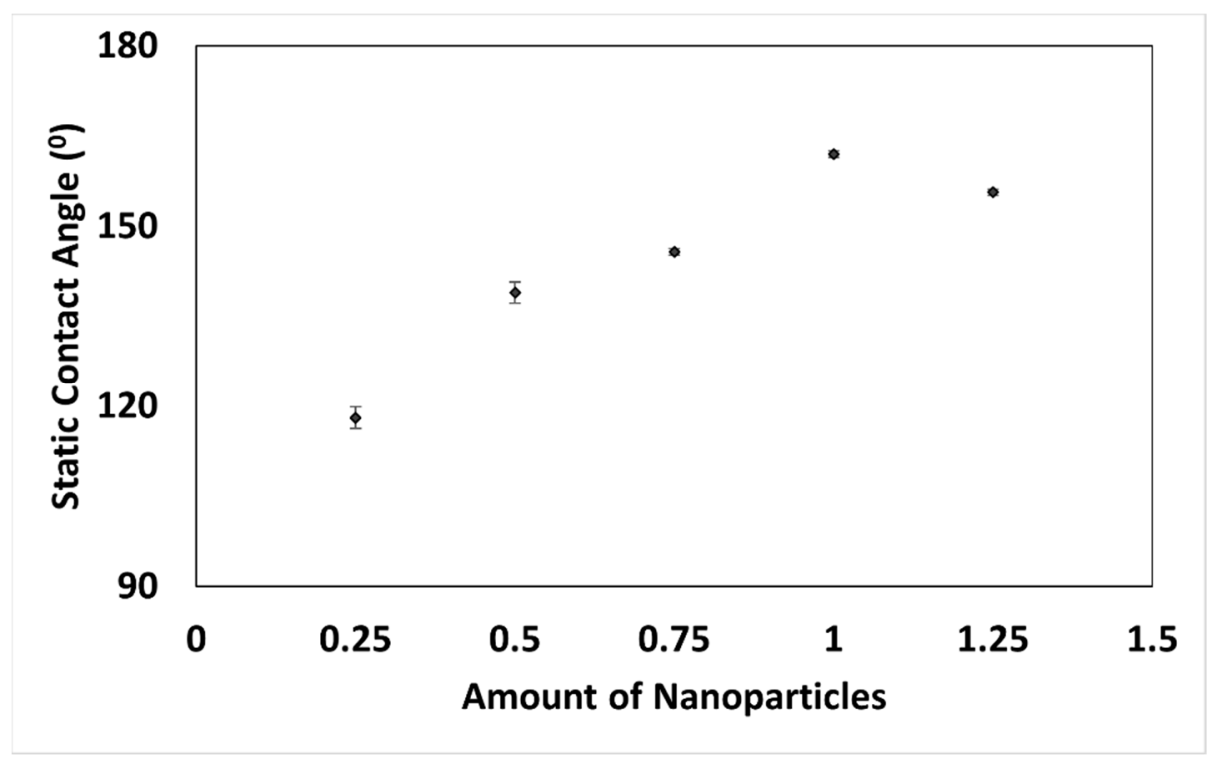

Figure 1. Variation in contact angle with respect to the amount of silica particles in $1 \mathrm{~g}$ of Epoxy.

\subsection{Surface Morphology and Chemical Composition}

Figure 2 shows the Scanning Electron Microscopy (SEM) images obtained for the nanocomposite superhydrophobic coating at different levels of magnifications. The coating's surface appears like a honeycomb structure. At higher magnification, the nanoparticles dispersed uniformly within the network structure are visible. The microscale roughness, contributed by the honeycomb-like structure, along with the nanoscale roughness, contributed by the silica nanoparticles, will result in a hierarchical structure that improves the hydrophobicity of the coating.

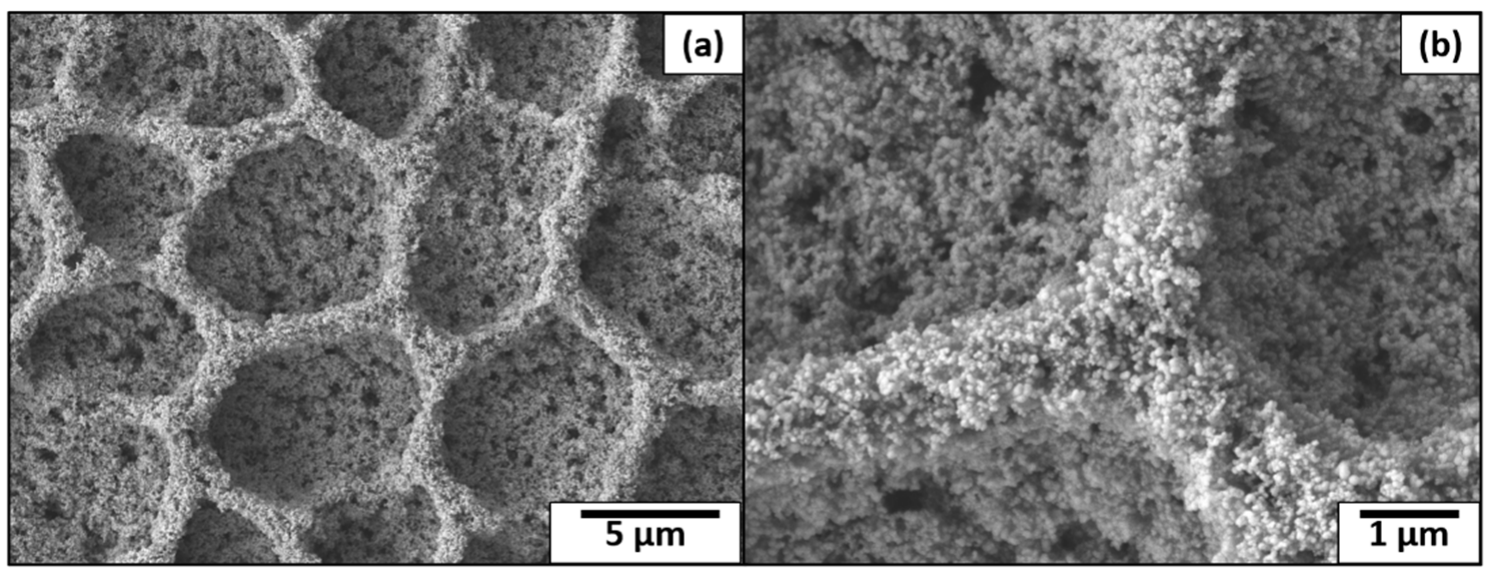

Figure 2. SEM images of superhydrophobic nanocomposite coating at (a) $\times 4300$ magnification, and (b) $\times 1600$ magnification.

An energy-dispersive X-ray spectroscope (EDX) was used to verify the elemental composition of the nanocomposite superhydrophobic coating. Figure 3 shows the EDX spectrum obtained for the epoxy-based nanocomposite superhydrophobic coating. The presence of four elements - namely silicon $(\mathrm{Si})$, oxygen $(\mathrm{O})$, carbon $(\mathrm{C})$, and nitrogen $(\mathrm{N})$ -was confirmed by the EDX data. Silica nanoparticles present in the nanocomposite coating solution explains the presence of silicon and oxygen, whereas the presence of peaks 
corresponding to carbon and nitrogen can be explained by the chemical ingredients within the epoxy resin used.

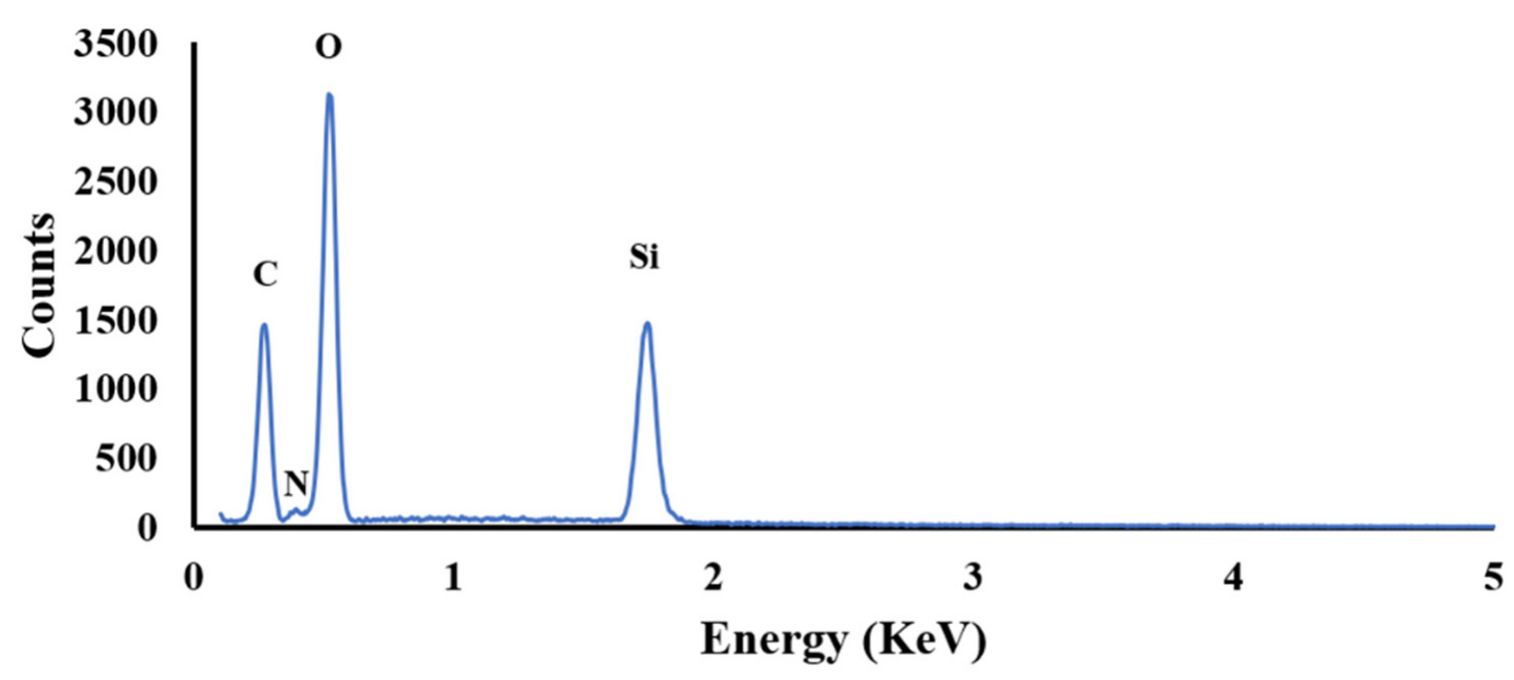

Figure 3. EDX spectrum for nanocomposite superhydrophobic coating.

\subsection{Abrasion Resistance of the Coating}

In view of practical applications, durability and mechanical stability are very important requirements for a superhydrophobic coating to be used as a functional anticorrosion coating. Quantitative analysis of abrasion resistance provides valuable information about the durability and mechanical stability of the coating tested. The abrasion resistance of the fabricated epoxy-based nanocomposite coating was analyzed using two distinct abrasion tests. The first test was a manual linear abrasion test using a 240-grit sandpaper as the abrading surface. During the abrasion test, the nanocomposite coating was moved against the abrading surface under an applied normal pressure of $7.75 \mathrm{kPa}$. The nanocomposite coating sample under applied pressure was moved for a total distance of $20 \mathrm{~cm}$ in one cycle of abrasion. The specimen was rotated by $90^{\circ}$ after $10 \mathrm{~cm}$ in each cycle, to introduce evenly distributed abrading action on the coating's surface. The substrate's surface was cleaned with a strong stream of air to remove any debris or abrasive particle after each abrasion cycle, prior to the measurement of contact angles. Figure 4 shows the variation in static contact angles for the nanocomposite coating, with reference to the number of abrasion cycles. The highest decrease in the static contact angle within a single abrasion cycle was observed for the first abrasion cycle, where the static contact angle was reduced from $162^{\circ}$ to $157^{\circ}$, resulting in a decrease of $5^{\circ}$. This high reduction in the first cycle can be explained by the delicate nature of the fine structures within the hierarchical nanocomposite structures. After the first cycle of abrasion, the rate of decrease in contact angle was considerably low. The nanocomposite coating maintained superhydrophobic behavior up to 20 cycles of abrasions, as the static contact angles remained over $150^{\circ}$ up to 20 cycles of abrasions. Upon further abrasion, the static contact angle was observed to decrease at a very low rate. The static contact angles were well over $145^{\circ}$ up to 30 cycles of abrasions and reduced by only $2^{\circ}$ for the next 10 cycles of abrasions. Finally, after 50 cycles of abrasions, the static contact angle was measured to be over $142^{\circ}$. Although the nanocomposite coating did not remain superhydrophobic after 50 cycles of abrasions, the nanocomposite coating can be considered to be fairly hydrophobic due to the considerably high static contact angle, and hence, the durability can be considered to be sufficient. 


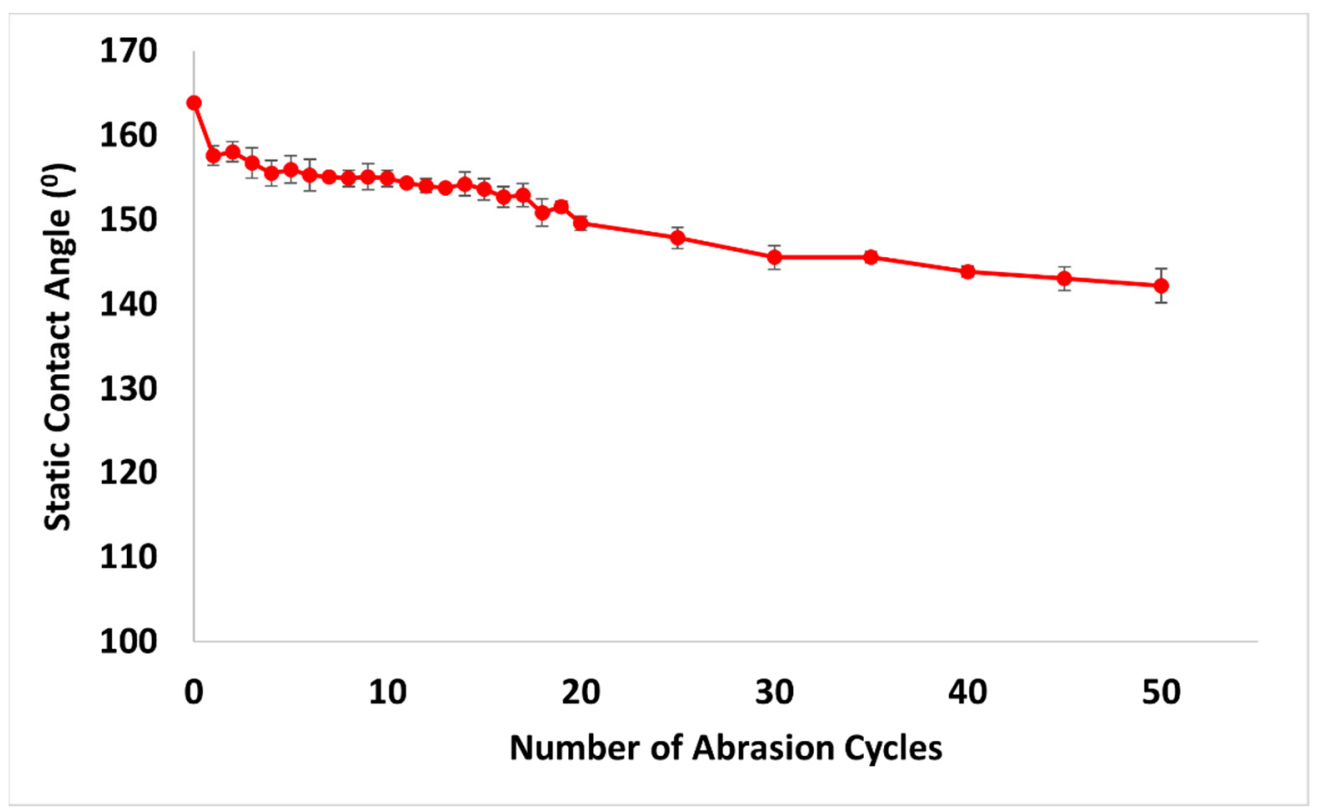

Figure 4. Static contact angles after abrasion against a 240-grit sandpaper with $7.75 \mathrm{kPa}$ normal load.

The nanocomposite superhydrophobic coating developed in this work is superior to previous superhydrophobic coatings tested for abrasion resistance with same type of manual abrasion test [22]. The reduction in static contact angle was very small for the current coating as compared to that for previous coatings tested with the same methodology. In case of a set of previously reported coatings, the reduction in static contact angle after 50 abrasion cycles with an applied pressure of $7.75 \mathrm{kPa}$ was reported to be over $40^{\circ}$, whereas in this work, the range of reduction was measured to be close to $20^{\circ}$, which shows the superior nature of the current nanocomposite superhydrophobic coating in terms of abrasion resistance, as compared to previously reported coatings [22].

In the second abrasion test, the abrading action was introduced by an automated Taber linear abrader under an applied normal pressure of $29.9 \mathrm{kPa}$. The abradant material used for the abrading action was CS-10F Calibrase (1.26 cm in diameter), which is capable of producing mild abrading action. The stroke speed for the linear motion was set at a constant value of 15 cycles $/ \mathrm{min}$. The static contact angle was measured after two linear abrasion cycles. Figure 5 shows the variation in static contact angles for the nanocomposite superhydrophobic coating, with respect to the number of abrasion cycles. Like the case of the manual abrasion test, the highest decrease in the static contact angle within a single abrasion cycle was observed for the first abrasion cycle, where the static contact angle reduced from $162^{\circ}$ to $155^{\circ}$, resulting in a decrease of $7^{\circ}$. After the first cycle of abrasion, the rate of decrease in contact angle was considerably low. The nanocomposite coating maintained superhydrophobic behavior up to 10 cycles of abrasions, as the static contact angles remained over $150^{\circ}$ up to 10 cycles of abrasions. Upon further abrasion, the static contact angle was observed to decrease at a very low rate. The static contact angles were over $142^{\circ}$ up to 20 cycles of abrasions. Finally, after 30 cycles of automated Taber abrasions at a high applied pressure of $29.9 \mathrm{kPa}$, the static contact angle was measured to be close to $140^{\circ}$. Although the nanocomposite coating did not remain superhydrophobic after 30 cycles of abrasions, the nanocomposite coating can be considered to be fairly hydrophobic due to the considerably high static contact angle. The coating can be considered to be fairly durable, taking into account the final static contact angle after 30 cycles of automated Taber linear abrasions and also the high applied pressure used in this abrasion test. 


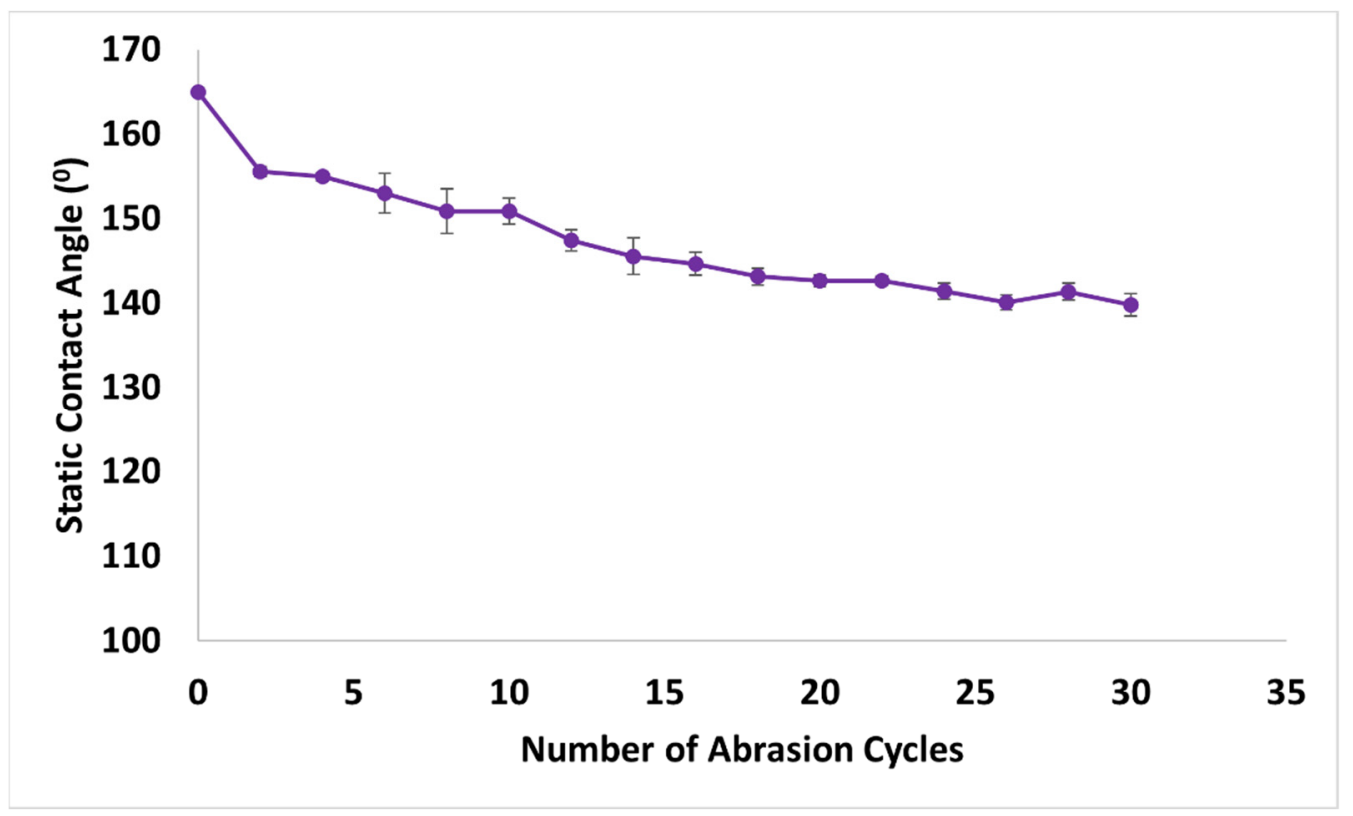

Figure 5. Static contact angles after Taber abrasion test against $29.9 \mathrm{kPa}$ applied normal load.

Like the observations made for the results from manual abrasion test, the results obtained from automated Taber linear abrasion were also compared against previous superhydrophobic coatings tested for abrasion resistance with same testing methodology [22]. The reduction in static contact angle for a previously reported superhydrophobic coating tested with same applied pressure and number of abrasion cycle was reported to be in the range of $50^{\circ}$, whereas for the current coating, the reduction is less than $23^{\circ}$, which shows the superior abrasion resistance of the current coating.

\subsection{Mechanical Properties of the Coating}

The nanomechanical properties of the fabricated nanocomposite coating, such as Berkovich hardness and reduced modulus, were measured using a nanoindentation experiment. The properties were calculated from the unloading portion of the force-displacement curve obtained for displacement-controlled indentations. A series of displacement-controlled indentations were performed on the sample, with the displacement value ranging from $500 \mathrm{~nm}$ to $4500 \mathrm{~nm}$ with an interval of $500 \mathrm{~nm}$. A total of 4 repetitions were performed for nanoindentation tests and the average values are reported. The thickness of the coating was measured to be in the range of $15 \mu \mathrm{m}$ to $16 \mu \mathrm{m}$. Figure 6 shows the Berkovich hardness values recorded for various displacement values. The average Berkovich hardness for the fabricated nanocomposite coating was found to be $0.20 \pm 0.07 \mathrm{GPa}$. Figure 7 shows the reduced modulus values recorded for various displacement values. The average reduced modulus for the fabricated nanocomposite coating was found to be $8.11 \pm 0.93 \mathrm{GPa}$. The nanomechanical properties for blank epoxy resin were also measured for comparison. The average Berkovich hardness for the blank epoxy resin was found to be $0.24 \pm 0.05 \mathrm{GPa}$. The average reduced modulus for the blank epoxy resin was found to be $3.99 \pm 0.73 \mathrm{GPa}$. 


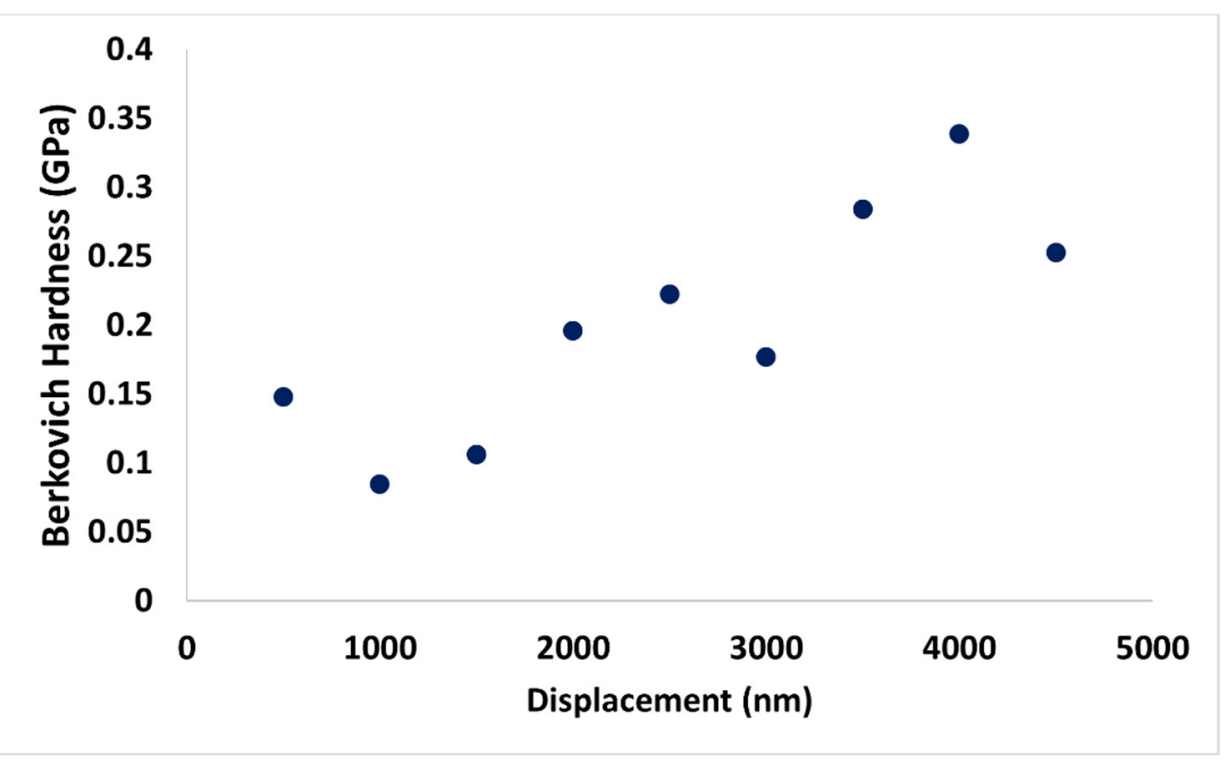

Figure 6. Berkovich hardness value measured on nanocomposite coating using nanoindentation.

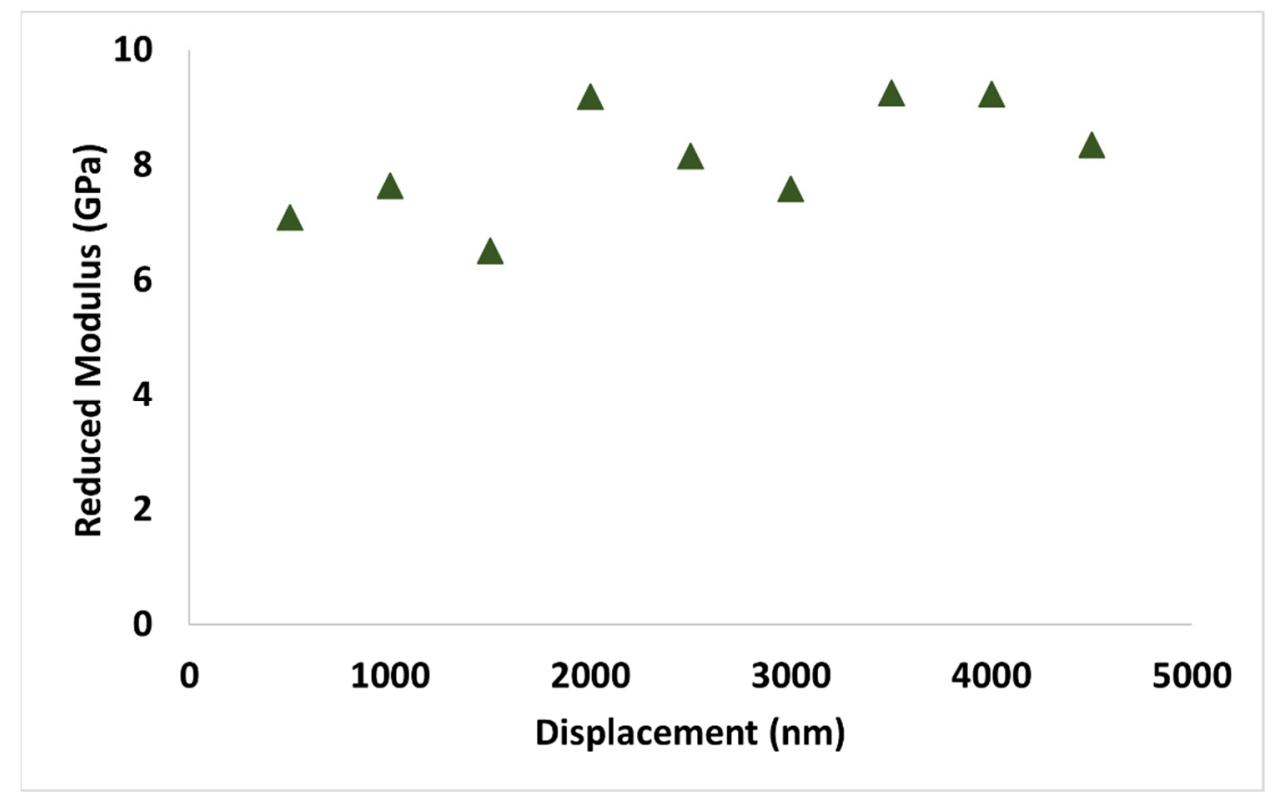

Figure 7. Reduced modulus value measured on nanocomposite coating using nanoindentation.

Unlike static contact angle measurements, abrasion resistance tests, and microscopy imaging for surface topography, measurement of nanomechanical properties of superhydrophobic coatings is not very popular in terms of the characterization of coatings. It can be considered to be a good approach for understanding the variation in mechanical properties with respect to the inclusion of various constituents within the nanocomposite coating, and also, in a broader sense, it will be an effective tool for comparing various coatings. Upon comparing the Berkovich hardness for the developed superhydrophobic nanocomposite coating and the blank epoxy resin, it can be observed that the blank epoxy resin has a higher hardness value. This observation is surprising, owing to the fact that silica is much harder than the blank epoxy resin and silica is acting like a reinforcing agent within the nanocomposite coating. The reason for reduced hardness for nanocomposite superhydrophobic coating could be the less dense and porous structure of the coating as characterized by the SEM images. 


\subsection{Corrosion Test by AFM and Accelerated Corrosion}

The corrosion resistance of the fabricated nanocomposite coating was evaluated at nanoscale by studying the evolution of surface topography using atomic force microscopy after different stages of accelerated corrosion. Between successive AFM topography scans, the accelerated corrosion process was simulated with the aid of a potentiostat along with a $3.5 \mathrm{wt} . \% \mathrm{NaCl}$ aqueous solution as the electrolyte at an applied potential of $90 \mathrm{mV}$ versus open circuit potential. The surface morphology was scanned on the test surface within a selected area before performing any accelerated corrosion, and these scans were designated as the initial scans for both the bare aluminum alloy and the nanocomposite superhydrophobic coating. After obtaining the initial scans, the sample was taken out of the atomic force microscope and accelerated corrosion was performed on the sample for a duration of one minute. After accelerated corrosion was performed, the same area was identified and scanned to retrieve the surface morphology. This process was repeated to obtain successive AFM topography scans for the same sample after two minutes and three minutes of corrosion. For the superhydrophobic nanocomposite coating's surface, there was no variation in the surface morphology, according to the AFM topography images obtained for different stages of accelerated corrosion. This behavior can be explained by the superior corrosion resistance of the superhydrophobic nanocomposite coating. The superhydrophobic nanocomposite coating was exposed to accelerated corrosion for a long duration of $60 \mathrm{~min}$ with the same conditions as of 1,2, and $3 \mathrm{~min}$ to emphasize the anticorrosion behavior of the fabricated nanocomposite coating. The AFM topography scan after this prolonged accelerated corrosion showed that the surface morphology remained unchanged and this observation was confirmed by the line analysis performed at arbitrarily selected locations. In the case of bare aluminum alloy, the same accelerated corrosion experiment was repeated with successive AFM topography imaging. There was clear deviation in surface morphology between successive scans. After 2 min of accelerated corrosion, visible changes were observed on the bare aluminum alloy, and the corrosion was found to be severe on bare aluminum alloy after $3 \mathrm{~min}$ of accelerated corrosion.

Figure 8 shows the variation in surface morphology for bare aluminum alloy. According to the surface morphology images for bare aluminum alloy in Figure 8, it can be observed that the surface morphology was slightly changed after one minute of accelerated corrosion and after $2 \mathrm{~min}$ of accelerated corrosion. Initiation of corrosion was observed after $3 \mathrm{~min}$ of accelerated corrosion, and it is clearly visible in Figure 8d. Figure 9a-e shows the Z-height line analysis performed for bare aluminum alloy substrate. The line analysis presented in Figure 9e clearly shows that there was variation in the surface morphology, as depicted by the huge deviation in Z-height at the identical location between successive scans. The pit-like morphology was measured to have a depth close to $2 \mu \mathrm{m}$. Line analysis performed at other locations where severe corrosion was observed in Figure $9 \mathrm{~d}$ also exhibited similar results.

Figure 10 shows the three-dimensional topography scan images for the superhydrophobic nanocomposite coating at different stages of accelerated corrosion. Figure 10d shows the surface topography after $60 \mathrm{~min}$ of accelerated corrosion to highlight the anticorrosion property of the nanocomposite coating as opposed to the case of bare aluminum alloy substrate. Unlike the deviations observed in the case of bare aluminum alloy, surface topography images for the superhydrophobic nanocomposite coating showed no variations, which means the surface structures were intact. Figure 11a-e shows the Z-height line analysis for the superhydrophobic nanocomposite coating at different stages of accelerated corrosion. The line analysis performed on the successive scans for superhydrophobic nanocomposite coating exposed to accelerated corrosion overlaps each other according to Figure 11e, and this clearly indicates that there was no change for the surface features. As the surface features remained intact, even after a prolonged exposure to accelerated corrosion for a duration of $60 \mathrm{~min}$, the anticorrosion behavior of the developed superhydrophobic nanocomposite coating can be confirmed at higher resolution. The observations 
made on the superhydrophobic nanocomposite coating after the AFM corrosion test are similar to those from previously reported corrosion tests using AFM [23].
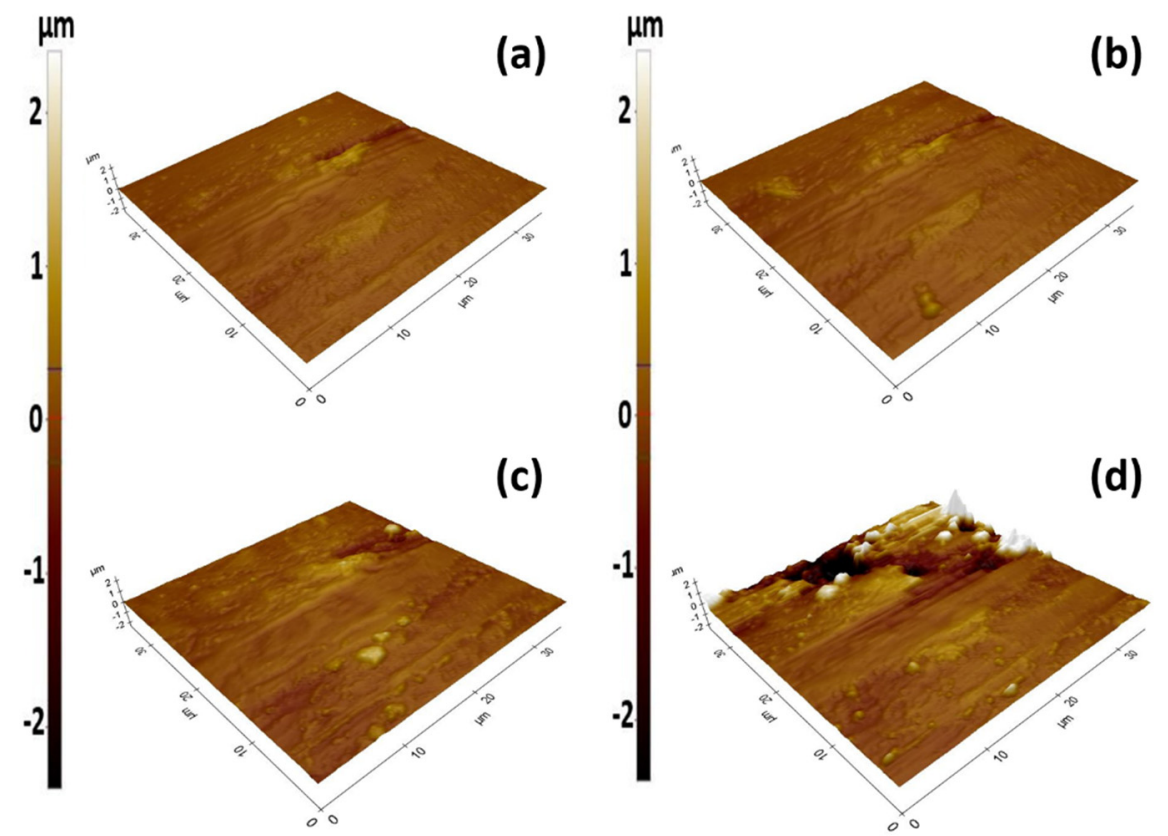

Figure 8. Three-dimensional surface topography image for bare aluminum alloy at (a) initial state, (b) after 1 min of accelerated corrosion, (c) after 2 min of accelerated corrosion, (d) after 3 min of accelerated corrosion.
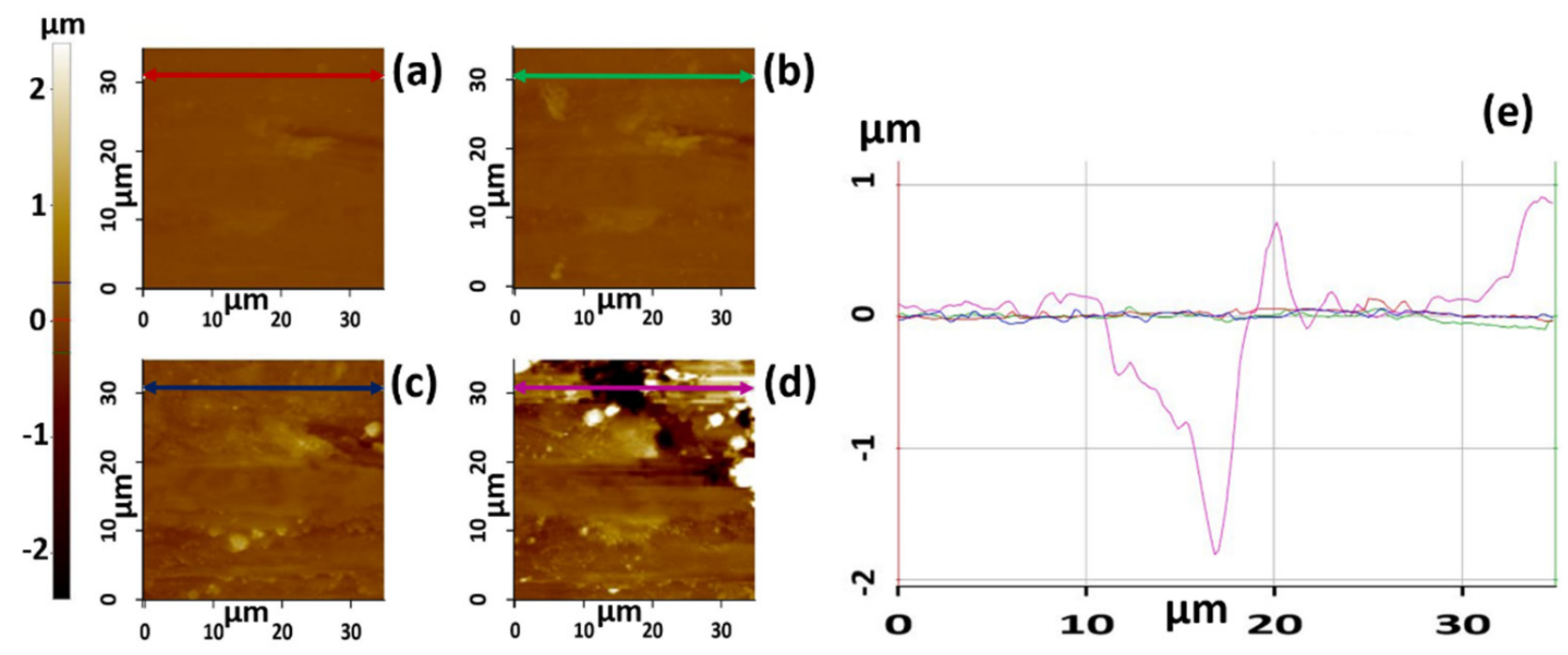

Figure 9. Surface topography of bare aluminum alloy at (a) initial state, (b) after 1 min of accelerated corrosion, (c) after 2 min of accelerated corrosion, (d) after 3 min of accelerated corrosion, (e) Z-height line analysis. 


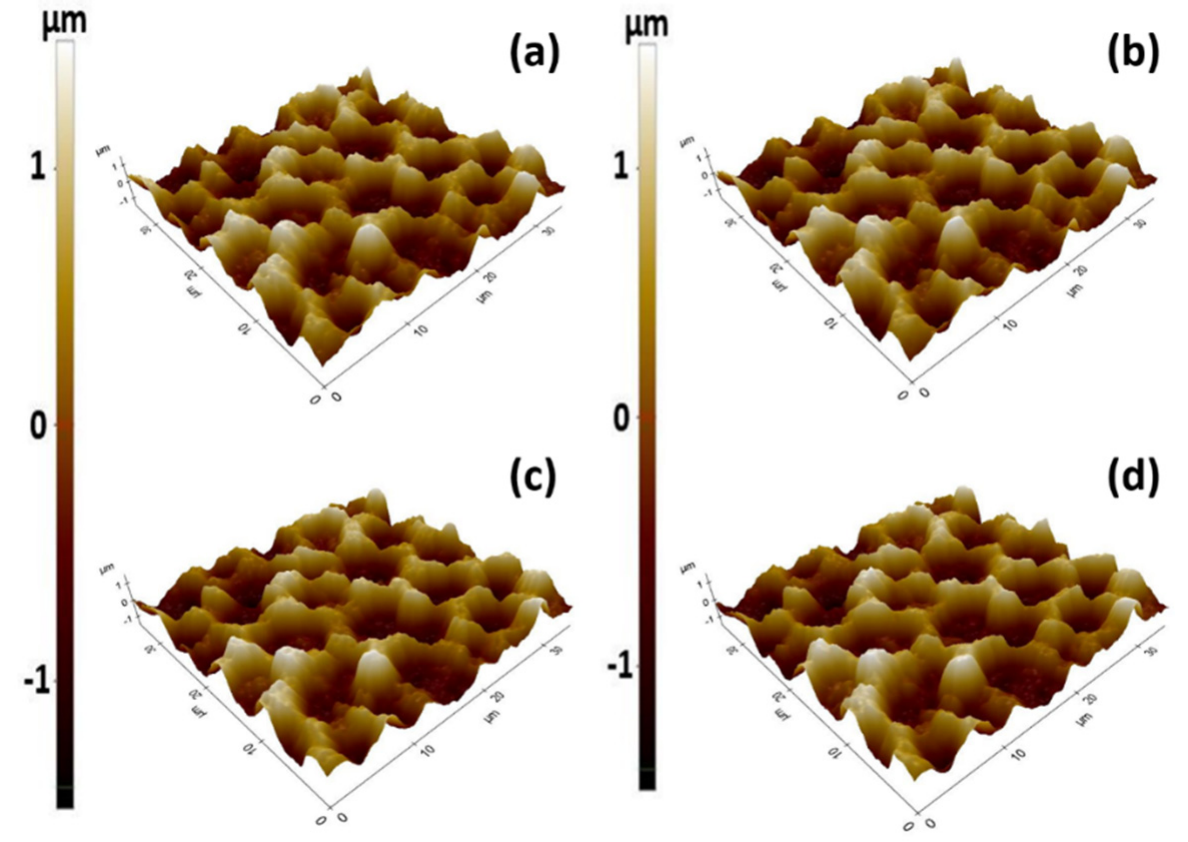

Figure 10. Three-dimensional surface topography image for superhydrophobic nanocomposite coating at (a) initial state, (b) after 1 min of accelerated corrosion, (c) after 3 min of accelerated corrosion, and (d) after 60 min of accelerated corrosion.
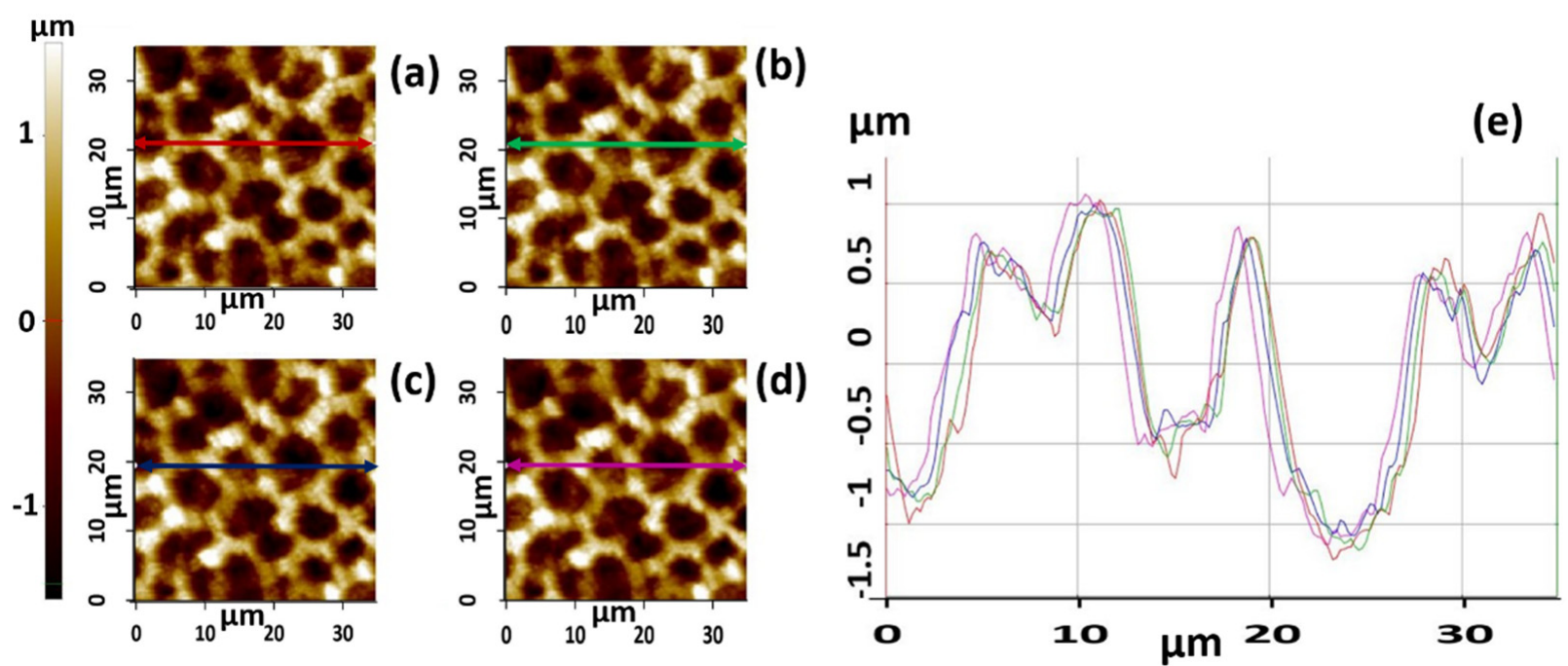

Figure 11. Surface topography of superhydrophobic nanocomposite coating at (a) initial state, (b) after 1 min of accelerated corrosion, (c) after $3 \mathrm{~min}$ of accelerated corrosion, (d) after $60 \mathrm{~min}$ of accelerated corrosion, (e) Z-height line analysis.

\subsection{Potentiodynamic Polarization Test}

To quantitatively study the corrosion phenomenon on bare aluminum alloy and the corrosion resistance of fabricated nanocomposite coating, potentiodynamic polarization tests were performed on both the substrates. Corrosion parameters, such as corrosion current density, corrosion potential, and corrosion rate, were quantified for both bare aluminum alloy and superhydrophobic nanocomposite coating with the aid of Tafel extrapolation of the polarization curves. Both the substrates were tested under identical test conditions. The sample was immersed in a $3.5 \mathrm{wt} . \% \mathrm{NaCl}$ aqueous solution for a duration of $24 \mathrm{~h}$ prior to the potentiodynamic polarization experiment. Figure 12 shows the potentiodynamic polarization curves for both bare aluminum alloy and superhydrophobic 
nanocomposite coating. The corrosion potential for bare aluminum alloy was found to be $-575 \mathrm{mV}$, whereas the same for superhydrophobic nanocomposite coating was found to be close to $-510 \mathrm{mV}$. As the superhydrophobic nanocomposite coating has more positive corrosion potential, it can be inferred that the superhydrophobic nanocomposite coating is less susceptible to undergo corrosion. The corrosion current density $\left(\mathrm{J}_{\text {corr }}\right)$ for bare aluminum alloy was found to be $57.80 \mu \mathrm{A} / \mathrm{cm}^{2}$, whereas the same value for superhydrophobic nanocomposite coating was found to be $14.82 \mathrm{nA} / \mathrm{cm}^{2}$. The reduction in corrosion current density is in the order of three, which means the degree of corrosion resistance introduced by superhydrophobic nanocomposite coating is very high. The polarization resistance $\left(R_{p}\right)$ for bare aluminum alloy was found to be $13.79 \mathrm{k} \Omega$, whereas the value for the same parameter was found to be $7.89 \mathrm{M} \Omega$ in the case of superhydrophobic nanocomposite coating. The corrosion rate for bare aluminum alloy was estimated to be $176.75 \times 10^{-3} \mathrm{~mm} /$ year, whereas for the superhydrophobic nanocomposite coating, the corrosion rate was estimated to be $486.99 \times 10^{-6} \mathrm{~mm} /$ year. Considering all the corrosion parameters, the fabricated superhydrophobic nanocomposite coating can be categorized as a superior anticorrosion coating. The results of the potentiodynamic polarization test reiterates the observations from the corrosion analysis performed with the aid of AFM topography images.

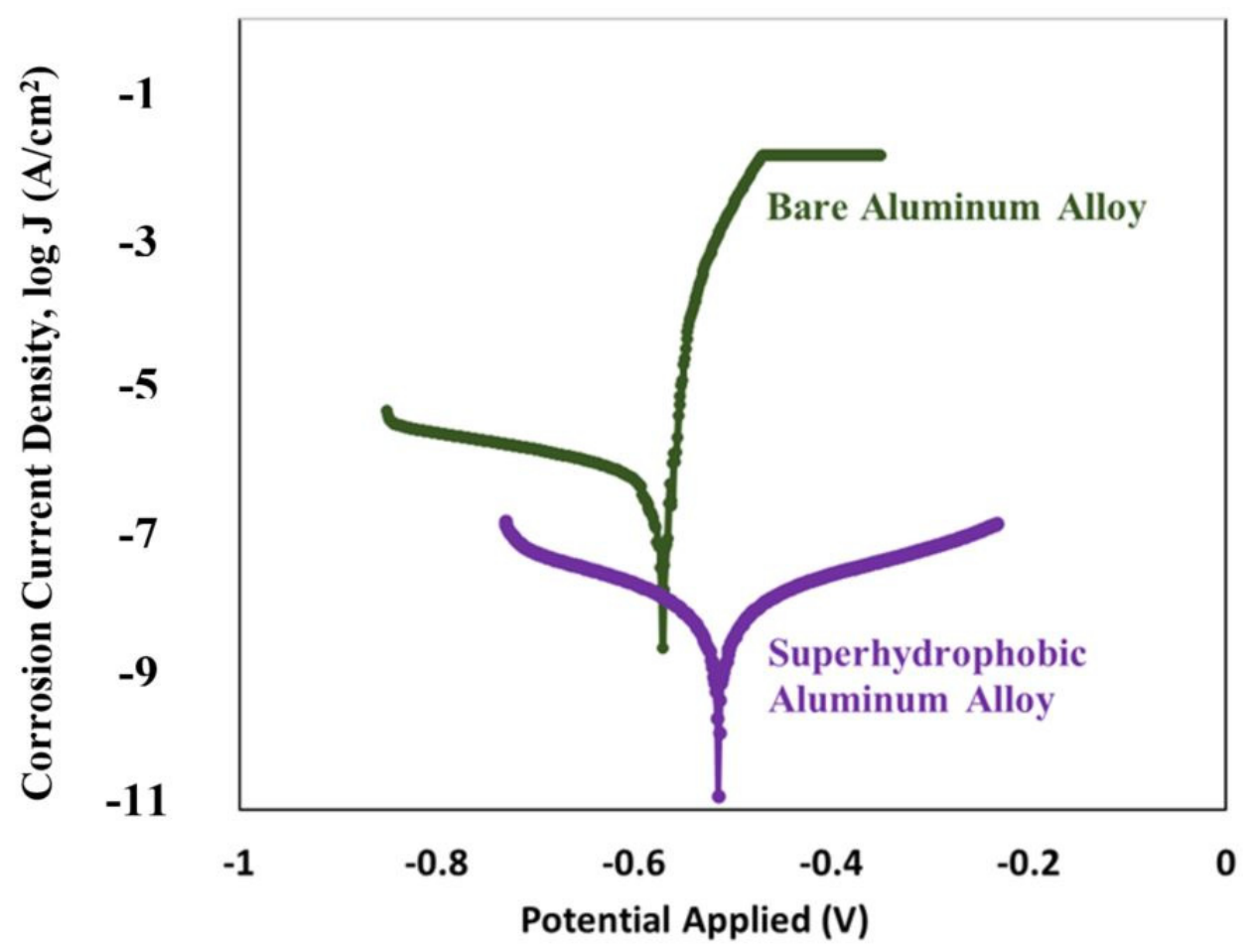

Figure 12. Potentiodynamic polarization curves for bare aluminum alloy surface and the superhydrophobic nanocomposite coating.

\section{Conclusions}

The nanocomposite superhydrophobic coating developed in this work can be considered to be durable and mechanically stable, providing good abrasion resistance and corrosion resistance. The nanocomposite coating composed of functionalized silica nanoparticles, epoxy resin, and toluene was found to be superhydrophobic in nature, as characterized by static contact angle measurements. The nanocomposite superhydrophobic coating was found to be mechanically durable, and superior to previously reported superhydrophobic coatings according to the results from identical abrasion tests. The nanomechanical properties of the nanocomposite coating were measured and the reason for a slight reduction in the nanocomposite coating's hardness, as compared to that of blank epoxy resin 
was identified and explained. The corrosion resistance of the developed nanocomposite superhydrophobic coating was analyzed using an advanced corrosion test using atomic force microscopy tests and accelerated corrosion. The corrosion parameters for both bare aluminum alloy, and nanocomposite superhydrophobic coating were estimated using potentiodynamic polarization test, and were compared. The observations from both corrosion tests reiterated the superior anticorrosion property of the developed nanocomposite superhydrophobic coating. The fabricated superhydrophobic nanocomposite coating can be used as an efficient anticorrosion coating for engineering applications where high corrosion resistance and durability are essential.

Author Contributions: C.-W.Y. designed and supervised the study; D.S. and L.N. performed the experiments; D.S. and C.-W.Y. analyzed the data; I.L. and G.T. contributed to the research guidance and resources; D.S. and C.-W.Y. wrote the paper. All authors have read and agreed to the published version of the manuscript.

Funding: This research received no external funding.

Acknowledgments: This work was supported by Center for Midstream Management and Science (CMMS) of Lamar University. The authors also appreciate the Center for Innovation, Commercialization and Entrepreneurship (CICE) at Lamar University for providing lab space.

Conflicts of Interest: The authors declare no conflict of interest.

\section{References}

1. Hou, B.; Li, X.; Ma, X.; Du, C.; Zhang, D.; Zheng, M.; Xu, W.; Lu, D.; Ma, F. The cost of corrosion in China. Npj Mater. Degrad. 2017, 1, 1-10. [CrossRef]

2. Azar, M.M.K.; Gugtapeh, H.S.; Rezaei, M. Evaluation of corrosion protection performance of electroplated zinc and zinc-graphene oxide nanocomposite coatings in air saturated $3.5 \mathrm{wt}$ \% $\mathrm{NaCl}$ solution. Colloids Surf. A Physicochem. Eng. Asp. 2020, 601, 125051. [CrossRef]

3. Askari, M.; Aliofkhazraei, M.; Ghaffari, S.; Hajizadeh, A. Film former corrosion inhibitors for oil and gas pipelines-a technical review. J. Nat. Gas Sci. Eng. 2018, 58, 92-114. [CrossRef]

4. Dai, M.; Liu, J.; Huang, F.; Zhang, Y.; Cheng, Y. Effect of cathodic protection potential fluctuations on pitting corrosion of X100 pipeline steel in acidic soil environment. Corros. Sci. 2018, 143, 428-437. [CrossRef]

5. Nazeer, A.; Madkour, M. Potential use of smart coatings for corrosion protection of metals and alloys: A review. J. Mol. Liq. 2018, 253, 11-22. [CrossRef]

6. Sebastian, D.; Yao, C.-W.; Lian, I. Mechanical durability of engineered superhydrophobic surfaces for anti-corrosion. Coatings 2018, 8, 162. [CrossRef]

7. Bahgat, A.; Mohamed, A.; Abdullah, A.; Almaadeed, M. Superhydrophobic and corrosion behavior of electrospun PVDF-ZnO coating. ECS Trans. 2015, 64, 57-67. [CrossRef]

8. Yao, C.W.; Sebastian, D.; Lian, I.; Günaydın-Şen, Ö.; Clarke, R.; Clayton, K.; Chen, C.; Kharel, K.; Chen, Y.; Li, Q. Corrosion resistance and durability of superhydrophobic copper surface in corrosive $\mathrm{NaCl}$ aqueous solution. Coatings 2018, 8, 70. [CrossRef]

9. Yang, W.; Li, J.; Zhou, P.; Zhu, L.; Tang, H. Superhydrophobic copper coating: Switchable wettability, on-demand oil-water separation, and antifouling. Chem. Eng. J. 2017, 327, 849-854. [CrossRef]

10. Wang, Z.; Li, Q.; She, Z.; Chen, F.; Li, L. Low-cost and large-scale fabrication method for an environmentally-friendly superhydrophobic coating on magnesium alloy. J. Mater. Chem. 2012, 22, 4097-4105. [CrossRef]

11. Jung, S.; Dorrestijn, M.; Raps, D.; Das, A.; Megaridis, C.M.; Poulikakos, D. Are superhydrophobic surfaces best for icephobicity? Langmuir 2011, 27, 3059-3066. [CrossRef]

12. She, Z.; Li, Q.; Wang, Z.; Li, L.; Chen, F.; Zhou, J. Novel method for controllable fabrication of a superhydrophobic CuO surface on AZ91D magnesium alloy. ACS Appl. Mater. Interface 2012, 4, 4348-4356. [CrossRef]

13. Zhu, X.; Zhang, Z.; Xu, X.; Men, X.; Yang, J.; Zhou, X.; Xue, Q. Facile fabrication of a superamphiphobic surface on the copper substrate. J. Colloid Interface Sci. 2012, 367, 443-449. [CrossRef]

14. Schaeffer, D.A.; Polizos, G.; Smith, D.B.; Lee, D.F.; Hunter, S.R.; Datskos, P.G. Optically transparent and environmentally durable superhydrophobic coating based on functionalized $\mathrm{SiO}_{2}$ nanoparticles. Nanotechnology 2015, 26, 055602. [CrossRef]

15. Zhang, Z.; Ge, B.; Men, X.; Li, Y. Mechanically durable, superhydrophobic coatings prepared by dual-layer method for anticorrosion and self-cleaning. Colloids Surf. A 2016, 490, 182-188. [CrossRef]

16. Sebastian, D.; Yao, C.; Lian, I. Multiscale corrosion analysis of superhydrophobic coating on 2024 aluminum alloy in a $3.5 \mathrm{wt} \%$ $\mathrm{NaCl}$ solution. MRS Commun. 2020, 10, 305-311. [CrossRef]

17. Qing, Y.; Yang, C.; Hu, C.; Zheng, Y.; Liu, C. A facile method to prepare superhydrophobic fluorinated polysiloxane/ZnO nanocomposite coatings with corrosion resistance. Appl. Surf. Sci. 2015, 326, 48-54. [CrossRef] 
18. Yu, J.; Qin, L.; Hao, Y.; Kuang, S.; Bai, X.; Chong, Y.M.; Zhang, W.; Wang, E. Vertically aligned boron nitride nanosheets: Chemical vapor synthesis, ultraviolet light emission, and superhydrophobicity. ACS Nano 2010, 4, 414-422. [CrossRef]

19. Boinovich, L.B.; Emelyanenko, A.M. The behaviour of fluoro-and hydrocarbon surfactants used for fabrication of superhydrophobic coatings at solid/water interface. Colloids Surf. A 2015, 481, 167-175. [CrossRef]

20. Tao, C.; Yan, H.; Yuan, X.; Yao, C.; Yin, Q.; Zhu, J.; Ni, W.; Yan, L.; Zhang, L. Synthesis of shape-controlled hollow silica nanostructures with a simple soft-templating method and their application as superhydrophobic antireflective coatings with ultralow refractive indices. Colloids Surf. A 2016, 501, 17-23. [CrossRef]

21. Sebastian, D.; Yao, C.-W. Effect of Poly (Dimethylsiloxane) binder in a silica-based superhydrophobic coating on mechanical properties, surface roughness, and wettability. MRS Commun. 2020, 10, 512-518. [CrossRef]

22. Sebastian, D.; Yao, C.-W.; Lian, I. Abrasion resistance of superhydrophobic coatings on aluminum using $\mathrm{PDMS} / \mathrm{SiO}_{2}$. Coatings 2018, 8, 414. [CrossRef]

23. Sebastian, D.; Yao, C. Simultaneous mapping of nanoscale topography and surface potential for the study of localized corrosion in 2024-T3 aluminum alloy and corrosion resistance introduced by a superhydrophobic coating. MRS Commun. 2021, 1-8.

24. Chatzigrigoriou, A.; Karapanagiotis, I.; Poulios, I. Superhydrophobic coatings based on siloxane resin and calcium hydroxide nanoparticles for marble protection. Coatings 2020, 10, 334. [CrossRef]

25. Karapanagiotis, I.; Grosu, D.; Aslanidou, D.; Aifantis, K. Facile method to prepare superhydrophobic and water repellent cellulosic paper. J. Nanomater. 2015, 2015, 1-9. [CrossRef]

26. Ntelia, E.; Karapanagiotis, I. Superhydrophobic Paraloid B72. Prog. Org. Coat. 2020, 139, 105224. [CrossRef] 